\title{
Penile Cancer pT0 TNM Finding v8
}

National Cancer Institute

\section{Source}

National Cancer Institute. Penile Cancer pTO TNM Finding v8. NCI Thesaurus. Code C140060.

Penile cancer with no evidence of primary tumor. (from AJCC 8th Ed.) 